hydrofluoric acid (HF) the decontamination of skin should focus on the inactivation of free fluoride ions. The present ex-vivo study investigated the effects of exposure duration and different antidotes on the potential systemic uptake of fluoride.

Methods The transdermal penetration of HF (c=30\%) through excised human skin was investigated by using static diffusion cells. After dermal application of the acid $\left(100 \mu \mathrm{l} / 0.64 \mathrm{~cm}^{2}\right)$ for $1 \mathrm{~min}$ the excess was removed using one dry cotton swab. Subsequently, the skin was cleaned with water, calcium gluconate $(\mathrm{CaGl})$, polyethylene glycol (PEG) 400 or hexafluorine ${ }^{(0}$ using a standardised protocol. In a further study, the application time was extended to $3 \mathrm{~min}$ to assess the effect of exposure duration. Chemical analyses of fluoride were carried out by GC-MS or via a fluoride-sensitive electrode.

Result Extension of the exposure time from 1 to $3 \mathrm{~min}$ led to an enhancement in the transdermal penetration of fluoride, however with similar penetration kinetics. At the end of experiments (6 hour) a 7-fold higher fluoride amount was detected in the receptor fluid (16 vs $114 \mu \mathrm{g}$ ). In all test series maximum flux was achieved within the first hour past exposure. Decontamination of the skin reduced the cumulative penetrated amount of fluoride by $28 \%$ (PEG 400), $49 \%$ (water) and $64 \%\left(\mathrm{CaGl} /\right.$ hexafluorine $\left.^{\odot}\right)$ compared to control.

Discussion The results indicate that the systemic uptake of fluoride ions and therefore possible systemic intoxication after exposure to hydrofluoric acid can be diminished by shortening the exposure duration. Reduction was further increased by decontamination of skin - most by substances which are known to supply the complexation of fluoride ions.

\section{DERMAL ABSORPTION OF FLUORIDE AND HYDROGEN IONS FOLLOWING TOPICAL EXPOSURE TO HYDROFLUORIC ACID}

Sonja Kilo* ${ }^{*}$ Kathrin Dennerlein, Gintautas Korinth, Thomas Göen, Hans Drexler. Institute of Occupational Medicine, Friedrich-Alexander-Universität Erlangen, Germany

\subsection{6/oemed-2018-ICOHabstracts.1168}

Introduction Despite being an extremely hazardous liquid, hydrofluoric acid (HF) is commonly used in industry due to its unique chemical properties. Chemically HF is defined as a 'weak' acid but fluoride ions can induce serious systemic toxic effects. Upon contact with low concentrated HF, symptoms such as pain or local lesions may be delayed.

The aim of this study was to characterise changes in intradermal $\mathrm{pH}$ and dermal fluoride penetration following $\mathrm{HF}$ application.

Methods A static diffusion cell model was used to study dermal fluoride penetration for 6-72 hour following application of varying amounts of $\mathrm{HF} \quad\left(\mathrm{c}=5 \%-50 \%, 100-160 \mu \mathrm{l} / 0.64 \mathrm{~cm}^{2}, 1-\right.$ $10 \mathrm{~min}$.) on human skin (thickness 0.9 or $2.5 \mathrm{~mm}$ ). Intra- and transdermal amounts of fluoride and intradermal $\mathrm{pH}$ were determined.

Result Transdermal penetration of fluoride increased exponentially with increasing HF concentration. In addition, penetration increased four-times by extending the exposure time from 1 to $3 \mathrm{~min}$. No further increase was seen with longer $\mathrm{HF}$ application (5 and $10 \mathrm{~min}$.). The increased amount of $\mathrm{HF}$ penetrated through $0.9 \mathrm{~mm}$ compared to $2.5 \mathrm{~mm}$ skin within one hour was levelled out at later time points. Intradermal accumulation of fluoride increased dose-dependently but to a lower degree. Intradermal $\mathrm{pH}$ dropped with increasing $\mathrm{HF}$ concentration and exposure time. Additionally, the lag time between $\mathrm{HF}$ application and onset of $\mathrm{pH}$ changes decreased with increasing HF concentration and application time.

Discussion The results of the present study show that following $3 \mathrm{~min}$. HF application maximal amounts of fluorides seem to have penetrated the skin. The longer lag time in $\mathrm{pH}$ drop with lower concentrated HF might explain the delay between HF contact and onset of pain.

\section{TOXICOLOGICAL EFFECTS OF REPETITIVE EXPOSURE TO MIG-WELDING FUME PARTICLES ON RAT PRECISION- CUT LUNG SLICES}

${ }^{1,2}{ }^{2}$ Krabbe*$^{*},{ }^{2} \mathrm{~S}$ Kanzler, ${ }^{1} \mathrm{~A}$ Esser, ${ }^{1} \mathrm{~T}$ Kraus, ${ }^{1} \mathrm{P}$ Brand, ${ }^{2} \mathrm{C}$ Martin. ${ }^{1}$ Institute of Occupational and Social Medicine, RWTH Aachen, Germany; ${ }^{2}$ Institute of Pharmacology and Toxicology, RWTH Aachen, Germany

\subsection{6/oemed-2018-ICOHabstracts.1169}

Introduction The proinflammatory effects of metal inert gas brazing (MIG) welding fumes containing zinc and copper have been demonstrated in humans. However, little is known about the specific effects on the lung. Here we examined the effects of different concentrations of welding fumes for repetitive exposure in rat precision-cut lung slices (PCLS).

Methods PCLS were prepared from agarose-filled lungs of male rats. To mimic a five day 'work week', PCLS were incubated in welding fume containing media with 1 and $0.1 \mu \mathrm{g} / \mathrm{ml}$ in a repetitive exposure model for 6 hours on 5 consecutive days. For the remaining 18 hours PCLS received incubation in standard incubation medium. For each day cytotoxicity was determined via WST-1 and LDH assay. To determine the maximal LDH release possible, PCLS were treated with Triton X100 as a positive control.

Result Over all days of consecutive treatment no significant reductions of mitochondrial activity determined via WST-1 could be found in comparison to untreated controls. LDH levels in supernatants increased up to $15 \%$ of levels of positive controls treated with Triton X-100, indicating no relevant toxicity.

Discussion This is the first time repetitive toxicological effects of welding fumes on the lung have been examined in isolated lung tissue with intact microanatomy. We demonstrate that a repeated exposure for up to five days has no relevant toxic effects on lung tissue in doses comparable to a realistic occupational exposure. Lung tissue slices could be a promising model to study toxicity of welding particles and need to be investigated further.

\section{MINERAL OIL IS A RISK FOR AUTOANTIBODIES INDUCTION}

Yoshiki Kurodar*. Department of Public health, Faculty of Medicine, University of Miyazaki, Japan

\subsection{6/oemed-2018-ICOHabstracts. 1170}

Introduction Mineral oil(hydrocarbon)is also used in many factories, and workers are exposed to a lot kind of mineral oil. It was reported that one element mineral oil named pristane induced inflammatory arthritis in rats and also induced lupus- 
associated autoantibodies such as antissDNA, anti-Su and antinRNP. Therefore, we investigated other mineral oils and evaluated the mechanism of autoantibodies induction.

Methods Female BALB/cJ (4 weeks old) were used. At 3 months of age, target mineral oil (pristine and other mineral oils) was injected intraperitoneal of each mouse. After 3 months later from injection, we sacrificed mice and extracted peritoneal cells and spleen cells from mice, and evaluated autoantibodies induction. And we also evaluate the expression of Tcell, macrophage cells and B cells surface receptors (Tcell: CD28, ICOS, CD40L, PD1. Macrophage cell and B cell: ICOS-L, CD40, PD-L1).

Result

1. We indicated autoantibodies (Anti-nuclear, anti-ssDNA, anti$\mathrm{Su}$ and anti-nRNP antibody) in mouse injected pristane and other mineral oils.

2. We detected $\mathrm{CD} 3 \zeta$ chain reduction in $\mathrm{T}$ cell of mineral oil injected mouse.

3. Expression of all surface receptors (CD28, ICOS, CD40L, PD1) of T cell were increased.

On the other hand, Macrophage cell and B cell surface receptors (ICOS-L, CD40, PD-L1) were decreased.

Discussion Our study indicated that mineral oil (pristane and other mineral oils) induced autoantibody, and $\mathrm{CD} 3 \zeta$ chain was reduced like to human autoimmune disease. Concerning to $\mathrm{T}$ cell, $\mathrm{T}$ cell receptors were stimulated but $\mathrm{CD} 3 \zeta$ chain was decreased. And macrophage cell and B cell were suppressed. Therefore, Mineral oil could stimulate $\mathrm{T}$ cell and suppress macrophage cell and $\mathrm{B}$ cell. But $\mathrm{CD} 3 \zeta$ of $\mathrm{T}$ cell was reduced. We think these phenomena could relate to induction of autoantibodies.

\section{NANOPARTICLES CONCENTRATION IN FROZEN EXHALED BREATH CONDENSATE AS AN INTERNAL DOSE OF NANOMATERIALS EXPOSURE}

\footnotetext{
${ }^{1,2}$ Saou-Hsing Liou*, ${ }^{2}$ Chung-Ching Wang, ${ }^{1}$ Wei-Te Wu, ${ }^{3}$ Wen-Che Hou, ${ }^{4}$ Hui-Ling Lee. ${ }^{1}$ National Institute of Environmental Health Sciences, National Health Research Institutes; ${ }^{2}$ Division of occupational medicine, Department of Family and Community Medicine, TriService General Hospital, National Defense Medical Centre; ${ }^{3}$ Department of Environmental Engineering, National Cheng Kung University; ${ }^{4}$ Department of Chemistry, Fu Jen Catholic University
}

\subsection{6/oemed-2018-ICOHabstracts. 1171}

Introduction Exhaled breath condensate (EBC) is an emerging and noninvasive specimen allowing the study of lung processes. EBC could be an ideal biological matrix, as it could provide information about the deposited dose. The purpose of this study is to examine whether exhaled UFP in EBC could be correlated with exposure levels or surrogate of nanoparticle exposure.

Methods $18 \mathrm{TiO}_{2}$-exposed nanomaterial workers and 23 nonexposed controls were recruited from nanotechnology factories. A questionnaire was used to collect personal information. EBC was collected by an ECoScreen turbo (Viasys GmbH, Höchberg, Germany) and stored at $-80^{\circ} \mathrm{C}$ until analysis. The particle size-number distribution of ultrafine particles (PM0.1) were assessed in the EBC samples with the NanoSight LM10 HS system (Nanosight Ltd., Salisbury, UK) using the Nanoparticle Tracking Analysis (NTA) method. The results were expressed as average size $(\mathrm{nm})$ mode size $(\mathrm{nm})$ concentration ((x108 \#particles/mL), \% of UFP and particles number of UFP).

Result The average size of particles (nm) in $\mathrm{TiO} 2$ exposed worker was smaller than non-exposed workers. The concentration of particles $\left(\mathrm{x} 10^{8}\right.$ \# particles $\left./ \mathrm{mL}\right)$ in $\mathrm{TiO} 2$ exposed worker was higher than non-exposed workers. However, there was no significant difference between $\mathrm{TiO}_{2}$ exposed and controls in the average size $(\mathrm{nm})$, mode size $(\mathrm{nm})$, concentration $\left(\mathrm{x} 10^{8}\right.$ \#particles $/ \mathrm{mL}$ ), \% of UFP and particles number of UFP. But we found that the particles number of UFP in females was significantly higher than in males.

Discussion The possible reason for no association between nanomaterial exposure and particle concentration in $\mathrm{EBC}$ may be due to the storage of $\mathrm{EBC}$ in $-80^{\circ} \mathrm{C}$ refrigerator for a period of time which may induce aggregation or agglomeration of nanoparticles. Further study is required to clarify the use of exhaled UFP in fresh EBC as exposure matrix.

\section{VOC'S IN CONTAINER, STUDY OF HEALTH PROBLEMS IN 125 FRENCH DOCKERS}

1,2 D Lucas*, ' I Despres, ${ }^{1,2}$ D Jegaden, ${ }^{2,3}$ B loddé. 'Iroise Health Occupational service Brest France; ${ }^{2}$ French society of maritime Medicine Brest France; ${ }^{3}$ Center of Occupational Health and environmental Diseases Brest Teaching Hospital Brest France

\subsection{6/oemed-2018-ICOHabstracts. 1172}

Introduction The EOM society published four years ago, a specific questionnaire, FUMEX questionnaire, on health impact of fumigants and other VOC's in containers. The aims of this study were to evaluate exposure and health impact in dockers.

Methods Dockers are interviewed in face to face by a nurse or an occupational physician from Port occupational health centre of Le Havre and Brest from april to September 2015. Questionnaires were analysed by sphinx software.

Results 125 questionnaires were included and analysed. Mean age was 35 years, $46 \%$ were smokers. More than $80 \%$ declared not being exposed to fumigants or VOC's. Exposures were mostly described for refrigeration technicians (21\%), or during port engine driving, handling containers. Symptoms most frequently described were headaches (42\%), fatigue (50\%), sleeping disorders $(33,6 \%)$, and pulmonary irritation (31\%). Only $22.4 \%$ wore regularly protective equipment. Phosphine is the fumigant mostly mentioned.

Discussion Most exposed of port workers seem to be now refrigeration technicians and logistic workers. A lack of knowledge on risk and prevention's measures is evident and important. The FUMEX questionnaire is too complicated to be relevant for daily prevention in occupational health services. It's more needed for physicians or in hospital or researchers working with suspicious cases. A shorter and more comprehensible questionnaire was created.

\section{OCCUPATIONAL RISK FACTOR FOR LYMPHATIC OR HAEMATOPOIETIC CANCER: CASE-CONTROL STUDY USING OCCUPATIONAL CANCER MONITORING SYSTEM DATA}

SM Park*, JH Leem, HC Kim. INHA University Hospital, Incheon, South korea

10.1136/oemed-2018-ICOHabstracts. 1173 